\title{
The syllable's role in speech production: Are syllables chunks, schemas, or both?
}

\author{
LUDOVIC FERRAND and JUAN SEGUI \\ CNRS and Université René Descartes, Paris, France
}

\begin{abstract}
Two experiments, one using the masked priming technique combined with very brief prime exposures and the other using a new technique, the induction technique, were run in order to investigate the role of syllabic structure in speech production. Experiment 1 (masked priming) showed no effect when primes shared only the abstract syllabic structure without the phonological content, whereas the same picture stimuli produced a syllabic priming effect in Ferrand, Segui, and Grainger (1996, Experiment 4) when primes corresponded to full syllables. In contrast, the results of Experiment 2 (induction) showed that picture naming latencies were significantly faster when subjects had first read aloud a set of words with the same syllabic structure than when these words did not share the syllabic structure with the picture target. This result was also observed when the set was composed of nonwords. These results demonstrate that the abstract syllabic structure (independently of its phonological content) plays an important role in speech production depending on the task used.
\end{abstract}

In a recent study, Ferrand, Segui, and Grainger (1996) demonstrated that French subjects responded faster in word, nonword, or picture naming tasks when a masked orthographic prime corresponded to the first syllable of the stimulus than when it corresponded to a longer or a shorter segment than the first syllable. This masked priming technique involved presenting very briefly a masked prime stimulus followed immediately by a given target stimulus. Each prime corresponded to a complete syllable only in one of the two words: BA was exactly the first syllable of the word BA.LADE ${ }^{1}$ but was less than the first syllable of the word BAL.CON, whereas BAL was exactly the first syllable of BAL.CON but was more than the first syllable of BA.LADE. Thus, the word BA.LADE was named faster when preceded by the prime BA than when preceded by BAL, whereas the word BAL.CON was named faster when preceded by the prime BAL than when preceded by BA. Note that French is usually described as a syllable-timed language having clear syllabic boundaries, and stress is typically word final.

In a later report, Ferrand, Segui, and Humphreys (1997) extended these results to British English. In a word naming task, they showed a syllable priming effect for English words with clear initial syllable boundaries (such as

The authors would like to thank Randi Martin, Gary Dell, and two anonymous reviewers for their comments on an earlier version. They also thank Albert Costa for suggesting the use of the induction technique and Madeleine Leveille for programming expertise. Correspondence should be addressed to L. Ferrand, Laboratoire de Psychologie Expérimentale, CNRS and Université René Descartes, 28 rue Serpente, 75006 Paris, France (e-mail: ferrandl@idf.ext.jussieu.fr).
BAL.CONY), but no effect with ambisyllabic word targets (such as BALANCE, where the $/ 1 /$ belongs both to the first and to the second syllable). Furthermore, they demonstrated that, for words with clear initial syllable boundaries, naming latencies were faster only when primes formed the first syllable of the target, relative to a neutral condition (composed of percent signs, such as $\% \% \% \% \% \% \%$ ). In another experiment, they showed that the two possible initial syllables of ambisyllabic words facilitated word naming to the same extent, relative to the neutral condition. In a final experiment, they observed a syllable priming effect for $C V$ words with clear initial syllable boundaries (such as DI.VORCE). This result demonstrated that the previous syllable effect obtained in the first experiment for CVC words was not due to increased phonological and/or orthographic overlap.

Wheeldon and Levelt (1995) have used a production variant of the classical syllable monitoring task in speech perception (Mehler, Dommergues, Frauenfelder, \& Segui, 1981). Mehler et al. (1981) found that when subjects monitored for syllable targets (e.g., $/ \mathrm{pa} /$ and $/ \mathrm{pal} /$ ) in spoken French carrier words (e.g., PA.LACE and PAL.MIER), their responses were faster when the string of target segments corresponded to the first syllable of the target word (e.g., /pa/ in PA.LACE, /pal/ in PAL.MIER) than when it did not (e.g., /pal/ in PA.LACE, /pa/ in PAL.MIER). In Wheeldon and Levelt's production monitoring task, Dutch subjects (who had a good knowledge of English) were instructed to silently generate the Dutch translation of an auditorily presented English word and to monitor their production for a given syllable target. Wheeldon and Levelt replicated the syllable monitoring effect in Dutch: Re- 
sponses to targets were faster when they corresponded to the initial syllable of the carrier word than when they did not. According to these authors, these results provide evidence that subjects base their responses on the generation of a syllabified phonological representation.

Thus, the results obtained in French, English, and Dutch suggest that syllables are functional units in speech production. In these studies, the syllable played an important role. However, the syllabic frame and the segmental composition were confounded in these experiments. In the conditions where the prime and the target shared syllabic structure, they also shared segmental composition or phonological content (e.g., bal/BALCONY).

Theories of speech production hold two different views of the syllable (see Sevald, Dell, \& Cole, 1995, for a review). The first view is that syllables are chunks that specify their phonological content. Words are stored as strings of syllables, and each syllable is represented by a symbol that indicates its sounds. The second view is that syllables are schemas (or frames) that specify an abstract structure independently of its phonological content (e.g., consonant-vowel-consonant). For instance, the chunk view holds that such syllables as /sit/ and /bed/ are simply different chunks because the sounds are different, but, by the schema view, they are similar because they share the same structure (a CVC structure here).

Priming experiments conducted by Romani (1992), Costa (1995, 1997), and Meijer (1996) have shown that the word's syllabic structure can be primed. Romani studied the effect of shared syllabic structure on naming, using an interference paradigm in which subjects prepared to repeat heard nonwords. In a minority of cases, instead of the go signal to initiate repetition of the nonword, the subjects saw a word that they had to read aloud. The relation between the nonword prime and word target was manipulated. Reading latencies were faster when prime and target overlapped in syllabic structure and lexical features (such as 'margin-'kolp@k) ${ }^{2}$ than when there was no overlap with respect to stress and syllabic structure (such as 'margin-es'keed). In another experiment, Romani tried to separate the contribution of syllabic structure and lexical stress using full structural overlap (such as in 'wisdom-'lerj@t), only lexical stress overlap (such as in 'wisdom-'anlet), and no structural overlap (such as in 'wisdom-ga'pel), but no significant results were obtained. Unfortunately, several properties of the experimental design complicate the interpretation of these results. Romani used a reading paradigm, and the priming results might have been influenced by the reading-specific orthography-phonology conversion processes. Furthermore, the second experiment failed to replicate the significant difference between full and no structural overlap. The problem might be methodological: The paradigm used might be not sensitive enough to replicate the results.

Using an induction technique, Costa (1995, 1997) showed that picture naming latencies were significantly faster when Spanish subjects had first read aloud words with the same syllabic structure than when these words did not share the syllabic structure with the picture target.

More recently, Meijer (1996) used the translation naming task, in which subjects translate aloud words presented visually in a foreign language (English) into their native language (Dutch). Meanwhile, primes were presented auditorily, and the subject was told to ignore these words. The results showed that structural overlap led to facilitation in naming latencies. For instance, when primes shared the abstract syllabic structure with the target (e.g., 'bi.zon-'ZE.Nuw in Dutch), the target was produced significantly faster, relative to an unrelated priming condition (e.g., 'bor.stel-'ZE.NUW). Meijer replicated these results with monosyllabic words. These results support the hypothesis that structural properties of the word are stored and retrieved independently from the phonemic content of the word.

Sevald et al. (1995) also reported results that support the idea that the abstract structure of syllables is represented. In three experiments, speakers were asked to repeat pairs of phonological strings as often as possible in a 4-sec period. Speech rate was faster when both the structure and the content of the first phonological word were repeated in the first syllable of the second one, relative to a condition in which all or most of the sounds were repeated but the structure was not. They demonstrated an advantage for repeating the initial structure (e.g., KEM TIL.FER), but this effect was the same for repeating both content and structure (e.g., TIL TIL.FER). This suggests that the benefit may be due to repeating abstract structure only, since there was no advantage for repeating both structure and content. The results support the view that syllable structure is separable from phonemic content, and they are consistent with a view of syllables as abstract schemas, not chunks.

In summary, the available evidence is compatible with the view that structural properties of the word are stored and retrieved independently from the phonemic content of the word. Therefore, the results of previous experiments (Ferrand et al., 1996; Ferrand et al., 1997; Wheeldon \& Levelt, 1995) could have been due either to the repetition of particular syllable strings or to the repetition of syllable structure. In other words, these results could support either the chunk view or the schema view of the syllable.

The aim of the present study was to determine whether the abstract syllabic structure (independently of the phonological content or segmental composition) plays a role as a unit in the construction of the phonological frame. In the following experiments, the subject's task was to name words, nonwords, and pictures as quickly as possible. The experimental conditions differed in terms of the type of relationship between the prime and the target. In Experiment 1, using the masked priming technique combined with picture naming (see Ferrand et al., 1996), bisyllabic and trisyllabic target picture names were preceded by visual sequences that shared (e.g., dis $\% \% \% \% \%$-CAR.TABLE, di $\% \% \% \% \%$-CA.ROTTE) or did not share (e.g., di $\% \% \% \% \%$-CAR.TABLE, dis $\% \% \% \% \%$ - 
CA.ROTTE) the abstract syllabic structure without the phonological content. Using exactly the same picture stimuli primed by visual sequences that corresponded or did not correspond to the full initial syllable (with its phonological content), Ferrand et al. (1996) found evidence for a syllable priming effect. In Experiment 2, using a new technique called the induction technique, subjects had to perform two tasks. First, they had to read aloud a list of words or nonwords (inductors) as fast as possible. At the end of each list, a picture (target) was presented on the screen, and the subjects had to name it as fast as possible. Again, the experimental conditions differed in terms of the type of relationship between the set of inductors and the target: bisyllabic and trisyllabic target picture names were preceded by visual sequences that shared (e.g., dis.cours-CAR.TABLE, di.vorce-CA.ROTTE) or did not share (e.g., di.vorce-CAR.TABLE, dis.coursCA.ROTTE) the abstract syllabic structure without the phonological content. Experiment $2 \mathrm{~A}$ used word inductors, and Experiment 2B used nonword inductors.

\section{EXPERIMENT 1}

\section{Method}

Subjects. Twenty psychology students at René Descartes University, Paris, served as subjects for course credit. All were native speakers of French, with normal or corrected-to-normal vision.

Stimuli and Design. Ten pairs of monomorphemic bisyllabic and trisyllabic French words (taken from Ferrand et al., 1996, Experiment 4) corresponding to simple black-on-white drawings of common objects served as target pictures. The pairs of target picture names shared the same initial three phonemes (CVC) and were selected such that these phonemes made up the first syllable for one member of the pair and the first two (CV) phonemes formed the first syllable of the second member of the pair. Thus, in the pair CA.ROTTE-CAR.TABLE (meaning carrot-schoolbag in English), the initial CVC sequence corresponded to the first syllable of the word CAR.TABLE, whereas the CV sequence was the first syllable of the word CA.ROTTE. The average frequency was 31 occurrences per million for the CVC picture names (ranging from a minimum of 1 to a maximum of 130) and 35 occurrences per million for the $\mathrm{CV}$ picture names (ranging from a minimum of 1 to a maximum of 288 ; Imbs, 1971). The pictures were selected from a French book of pictures, were digitized (using an HP Scan Jet IIcx), and were edited with PhotoStyler. At a viewing distance of $60 \mathrm{~cm}$, the mean angular size of the pictures was $2.5^{\circ}$ horizontally and vertically. For each target picture, two types of primes were selected: (1) primes that shared the first abstract syllabic structure without its phonological content (e.g., dis $\% \% \% \% \%$-CAR.TABLE and di $\% \% \% \% \%$ CA.ROTTE) and (2) primes that shared neither the first abstract syllabic structure nor the phonological content (e.g., di $\% \% \% \% \%$-CAR.TABLE and dis $\% \% \% \% \%$-CA.ROTTE). Each picture target was primed by both a CVC and a CV prime, with the order of presentation of these priming conditions being counterbalanced across subjects, as in Ferrand et al. (1996). The two categories of picture targets (CVC and CV names) represented the factor type of target, whereas the two categories of primes represented the factor type of prime. The two factors were crossed in a $2 \times 2$ factorial design. Two groups of subjects were used to counterbalance the presentation order of a given picture target and its two corresponding set of primes. Thus, two orders of presentation were used, and each subject received ail the conditions and saw the target pictures twice in either of the two orders.

Procedure. The subjects were tested individually. Before starting the experiment proper, the subjects were given a booklet including all drawings (following Ferrand, Grainger, \& Segui, 1994). Next to each object was printed the word. The subjects were asked to examine al the drawings, to study their names, and to use only those names to refer to the pictures in the experiment. Primes and target pictures were presented in the center of the screen of a personal computer with a 70$\mathrm{Hz}$ refresh rate. They appeared as black on a white background. The masked prime procedure with the picture naming task used in the experiments of Ferrand et al. (1994) was adopted here. Each trial consisted of the following sequence of four stimuli presented on the same screen location. First, a forward pattern mask was presented for $500 \mathrm{msec}$. This was immediately followed by presentation of the prime for $29 \mathrm{msec}$, which was followed immediately by a backward pattern mask for $14 \mathrm{msec}$. This was immediately followed by presentation of the target picture in the same screen location as the masks. The target pictures remained on the screen until the subjects responded. Primes were always presented in uppercase letters and were always completely covered by the mask. The subjects were asked to fixate the middle of the forward mask and to name the depicted object as rapidly and as accurately as possible. The existence of a word prime was not mentioned. The computer recorded the naming times from target onset to the triggering of the voice key by the subject's response. The experimenter sat in the same room as the subject in order to check and note the responses. The next trial sequence followed after a 3 -sec delay. Stimulus presentation was randomized, with a different order for each subject. The estimated visibility of the primes was tested in earlier closely related experiments (Ferrand et al., 1994). The subject's task was to decide whether or not the prime was identical to the name of the picture target; in other words, the subjects performed a forced choice same-different judgment. The overall percent correct rate was $49 \%$. Moreover, the overall percent correct value was almost identical for high-frequency and low-frequency targets. This absence of a frequency effect provided further evidence that the subjects had very little information available from the prime stimuli. Therefore, it seems safe to conclude that very little precise information about the prime as a whole was available for conscious identification.

\section{Results}

Mean naming latencies and percentage of errors are given in Table 1. Latencies longer than $1,000 \mathrm{msec}$ were excluded (less than $1.5 \%$ of the data). An analysis of variance (ANOVA) was run with type of target ( $\mathrm{CV}$ or CVC picture names) and type of prime (CV or CVC primes) entered as main factors.

In an ANOVA conducted on the correct naming latencies and percentage of errors to picture targets, no main or interaction effects were significant in either the by-subjects or the by-items analyses (all $F \mathrm{~s}<1$, and $p \mathrm{~s}>.50$ ).

\section{Discussion}

The same picture stimuli that produced a syllabic priming effect in Ferrand et al. (1996, Experiment 4) did not produce a similar effect when primes shared only the abstract syllabic structure without the phonological content. This null result provides support for the hypothesis that syllables are chunks rather than schemas. However, there is at least one major difference between our experiments and those of Sevald et al. (1995) that might have been responsible for this difference. It is the use of different methodologies: repeating aloud in the Sevald et al. study and a masked priming technique combined with naming in the present experiment. Indeed, in the present experiment, a single prime was masked and did not involve overt production, whereas, in experiments that yielded positive results, the primes were produced overtly and repeatedly either together (Sevald et al., 1995) or before the target (Costa, 1995, 1997). Therefore, the conditions that seem to be necessary to demonstrate effects of abstract syllable structure are the overt production of repeated primes.

In Experiment 2, we used a task more similar to those used by Sevald et al. (1995). Subjects had to perform two tasks. First, they had to read aloud a list of words or nonwords (inductors) as fast as possible. At the end of each list, a picture (target) was presented on the screen, and the subjects had to name it as fast as possible. This induction technique (adapted from Costa, 1995, 1997) is based on the 
Table 1

Mean Naming Latencies (in Milliseconds) and

Percent Errors in Experiments 1, 2A, and 2B

\begin{tabular}{|c|c|c|c|c|c|}
\hline \multirow[b]{2}{*}{ Picture Targets } & \multicolumn{2}{|c|}{$\begin{array}{l}\text { CV Picture Targets } \\
\text { (e.g., ca.rotte) }\end{array}$} & \multicolumn{2}{|c|}{$\begin{array}{c}\text { CVC Picture Targets } \\
\text { (e.g., car.table) }\end{array}$} & \multirow[b]{2}{*}{ Mean } \\
\hline & Latency & $\%$ Error & Latency & $\%$ Error & \\
\hline \multicolumn{6}{|c|}{ Experiment 1} \\
\hline $\begin{array}{l}\text { CV primes } \\
\text { (e.g., DI\%\%\%\%\%) } \\
\text { CVC primes }\end{array}$ & 783 & 15 & 791 & 18.5 & 787 \\
\hline$M^{(\mathrm{e} . \mathrm{g} ., \mathrm{DlS} \% \% \% \%)}$ & $\begin{array}{l}780 \\
781.5\end{array}$ & 16.5 & $\begin{array}{l}785 \\
788\end{array}$ & 20 & 782.5 \\
\hline \multicolumn{6}{|c|}{ Experiment $2 \mathrm{~A}$} \\
\hline $\begin{array}{l}\text { CV word primes } \\
\text { e.g., di.vorce) }\end{array}$ & 616 & 9 & 671 & 11 & 643.5 \\
\hline $\begin{array}{l}\text { CVC word primes } \\
M^{\text {(e.g., dis.cours) }}\end{array}$ & $\begin{array}{l}668 \\
642\end{array}$ & 12 & $\begin{array}{l}621 \\
646\end{array}$ & 11 & 644.5 \\
\hline \multicolumn{6}{|c|}{ Experiment $2 \mathrm{~B}$} \\
\hline $\begin{array}{l}\text { CV nonword primes } \\
\text { (e.g., fu.maste) } \\
\text { CVC nonword primes }\end{array}$ & 720 & 13 & 755 & 12 & 737.5 \\
\hline$M^{\text {(e.g., fil.mor) }}$ & $\begin{array}{l}760 \\
740\end{array}$ & 12 & $\begin{array}{l}719 \\
737\end{array}$ & 10 & 739.5 \\
\hline
\end{tabular}

assumption that a sequence that repeats aspects of a plan should be easier to produce than one that requires the plan to be changed. We expected that subjects would have to plan the response and that they would benefit when aspects of the plan were repeated. Following Sevald and Dell (1994) and Sevald et al. (1995), a benefit for repeating some property of the utterance would be taken as evidence that this property is represented in speech planning. The induction technique was designed to confront subjects with the same initial syllabic structure using a repetition task. According to the editing view of speech planning (see Rosenbaum, Weber, Hazelett, \& Hindorff, 1986), a relevant structure in speech production can be retrieved faster if subjects can reuse it. If the syllabic structure is relevant as an abstract unit in speech production, its retrieval could be speeded up by reusing it through a repetition task.

\section{EXPERIMENTS 2A AND 2B}

\section{Method}

Subjects. Forty psychology students at René Descartes University, Paris, served as subjects for course credit: 20 in Experiment 2A (word inductors), and 20 in Experiment $2 \mathrm{~B}$ (nonword inductors). All were native speakers of French, with normal or corrected-to-normal vision.

Stimuli and Design. Exactly the same picture targets were used as in Experiment 1. In Experiment 2A, each picture target was preceded by a set of five CVC and CV word inductors, with the order of presentation of these priming conditions being counterbalanced across subjects, giving a total of 20 pictures and 100 words to name aloud. Experimental conditions were defined by the relationship between the inductor lists and the targets. The inductor lists were composed of items sharing the same initial syllabic structure. An example of the conditions used is given in Table 2. Note that the inductor's first syllable did not contain phonemes in the first syllable of the target picture. In Experiment 2B, the design was the same as in Experiment $2 \mathrm{~A}$, except for the use of nonword rather than word inductors. The nonwords were generated from CVC and CV French words by replacing (after the first three phonemes) a consonant with another consonant or a vowel with another vowel, in such a way that only legal syllables in French were used. Exactly the same picture targets were used as in Experiment 2A. For both Experiments $2 \mathrm{~A}$ and $2 \mathrm{~B}$, each target picture was presented twice to a given subject, paired with one of the two alternative set of inductors in the first half of the experiment and with the other possible prime in the second half. The two categories of picture targets (CVC and $\mathrm{CV}$ names) represented the factor type of target, whereas the two categories of inductor stimuli represented the factor type of inductor. The two factors were crossed in a $2 \times 2$ factorial design. Two groups of subjects were used to counterbalance the presentation order of a given picture target and its two corresponding set of inductors. Thus, two orders of presentation were used, and each subject received all the conditions and saw the target pictures twice in either of the two orders.

Procedure. Each trial had the following sequence: An inductor stimulus appeared (in uppercase) on the computer screen for $500 \mathrm{msec}$. The subjects read aloud the word (or the nonword) as fast and as accurately as possible. Another inductor was presented on the screen 500 msec after the offset of the inductor, and so on, until the end of the list. After the presentation of the last inductor of each list, a drawing appeared and remained on the screen until the subjects responded. The computer recorded the naming times from target onset to the triggering of the voice key by the subject's response (Sennheiser MD211N microphone). The experimenter sat in the same room as the subject in order to check and note the responses. Stimulus presentation was randomized, with a different order for each subject.

\section{Resuits}

Mean naming latencies and percentage of errors are given in Table 1 for Experiments $2 \mathrm{~A}$ and $2 \mathrm{~B}$. Latencies longer than $1,000 \mathrm{msec}$ were excluded (less than $1 \%$ and $1.5 \%$ of the data for Experiments $2 \mathrm{~A}$ and 2B, respectively). Separate ANOVAs were run for Experiments 2A and 2B, with type of target (CV or CVC picture names) and type of inductor (CV or CVC primes) entered as main factors. $F$ values are reported by subject $(F 1)$ and by items $(F 2)$.

Experiment 2A: Word inductors. The main effect of type of target was not significant $[F 1(1,17)<1 ; F 2(1,9)=$ 1.69], nor was the main effect of type of inductor (both $F$ s $<1$ ). On the other hand, the interaction between these two factors was significant $[F 1(1,17)=43.98, p<.001$; $F 2(1,9)=45.78, p<.001]$. The interaction reflects the fact that naming latencies were faster when CVC picture 
Table 2

Experimental Conditions Used in Experiment $2 A$

\begin{tabular}{lll}
\hline & CVC Inductors & CV Inductors \\
\hline Inductors & VICTOIRE & LIBRAIRE \\
& NUPTIALE & NOBLESSE \\
& LECTRICE & RETRAITE \\
& RUSTINE & FURIEUSE \\
& DISCOURS & DIVORCE \\
CVC targets & CARTABLE & CARTABLE \\
CV targets & CAROTTE & CAROTTE \\
\hline
\end{tabular}

targets were preceded by CVC inductors than when they were preceded by $\mathrm{CV}$ inductors $[F 1(1,17)=34.35$, $p<.001 ; F 2(1,9)=15.54, p<.01]$, and they were faster when $\mathrm{CV}$ picture targets were preceded by $\mathrm{CV}$ inductors than when they were preceded by CVC inductors $[F 1(1,18)=18.11, p<.001 ; F 2(1,9)=8.33, p<.02]$. An analysis of the error data showed no main or interaction effects (all $F \mathrm{~S}<1$ ).

Experiment 2B: Nonword inductors. The main effects of type of target and type of inductor were not significant in either analysis (all $F \mathrm{~s}<1$ ). On the other hand, the interaction of target and prime inductor was significant $[F 1(1,17)=22.88, p<.001 ; F 2(1,9)=15.27$, $p<.01]$. An analysis of the error data showed no main or interaction effects (all $F_{\mathrm{s}}<1$ ). As in Experiment $2 \mathrm{~A}$, the interaction reflects the faster naming latencies to CVC picture targets when preceded by CVC inductors than when preceded by $C V$ inductors $[F 1(1,17)=10.06$, $p<.01 ; F 2(1,9)=11.75, p<.01]$, and the faster RTs to $\mathrm{CV}$ picture targets when they are preceded by $\mathrm{CV}$ inductors than when they are preceded by CVC inductors $[F 1(1,17)=26.14, p<.001 ; F 2(1,9)=10.12, p<.02]$.

\section{Discussion}

When a target picture was preceded by a set of inductors that shared the same syllabic structure (without its phonological content) of the picture name's first syllable, naming latencies were faster than when inductors did not share the same syllabic structure with the first syllable of the picture's name. These results support the idea that the $a b$ stract structure of syllables is represented (Costa, 1995, 1997; Meijer, 1996; Sevald et al., 1995). The effect was entirely due to repeating abstract structure, since there was no phonological overlap. Indeed, in each experiment, the subjects benefited by repeating the structure of an initial syllable in the next syllable of the sequence, thus confirming the results of Sevald et al

A caveat to this explanation is the possibility that the effects are strategically induced by the present experimental technique. Subjects can discover a regularity in abstract syllabic structure: After having been presented with and pronounced five stimuli, words or nonwords, that all started out with, for instance, a CVC structure, the subjects might be prepared to pronounce yet another CVC syllable, the first syllable of the picture name, and not prepared to pronounce a syllable with a different structure. ${ }^{3}$ But this is unlikely for at least three reasons. First, in the debriefing, the subjects were asked if they used a specific strategy to perform the task, and none of them reported an ability to clearly discern the relationship between the (word and nonword) inductors and the picture targets. Second, the rhythm of presentation of the items was fast, making it difficult for the subjects to detect any regularity in the abstract syllabic structure. Third, Costa (1997) conducted similar experiments but added a neutral condition (composed of mixed CV and CVC structures). In four experiments, he found no evidence for an inhibition effect when subjects were not prepared to pronounce a syllable with a different structure (relative to the neutral condition). This suggests that it was not possible for the subjects to set up an expectancy of a particular syllable structure. Therefore, it seems unlikely that the present results were due to strategic anticipation effects.

The other interesting result is that this effect of syllabic structure was observed with word and nonword inductors. The processes used to produce pronounceable nonwords may not have been identical to normal retrieval, but the fact that the same effect was observed with both words and nonwords suggests that the syllabic effects we have demonstrated are not lexical in nature. The results we report are the first instance we know of in which syllabic effects have been reliably found for both words and nonwords. None of the previous reported experiments has yet provided data about the locus of the representation used in this task - that is, whether it is a lexical or nonlexical representation. To make the argument that the syllabic effects we have demonstrated are not lexical in nature, we showed that the syllabic effect still occurred with nonwords that follow the phonotactic rules of the language but that have no lexical entry.

\section{GENERAL DISCUSSION}

\section{A Mixed Model of the Syllable Using Both}

\section{Syllable Frames and Stored Syllable Chunks}

Experiment 2 provided evidence for an abstract syllabic effect in speech production in French, in contrast to Experiment 1, which argued against the existence of such an effect. One possible source of this difference in results is the task asked to the subject: In the masked priming technique combined with naming, the subjects did not pronounce the primes since they were heavily masked, whereas, in the induction technique, the subjects had to repeat aloud visual primes five times. Taking together the present results, the results obtained in French by Ferrand et al. (1996), as well as the results obtained in English by Ferrand et al. (1997), the data support a mixed model of the syllable (Dell, 1986; Levelt, 1989; MacKay, 1987), in which both frames and chunks are linked to words.

\section{The Editing View of Speech Planning}

Theories of speech production hold that speech must be planned (Levelt, 1989). Experiment 2 was motivated by an editing view of speech planning, in which a new plan can reuse part of an earlier one if aspects of the sequence are repeated (Rosenbaum et al., 1986). According to the editing view, a plan is a schema with variables to which values are assigned. In the case of the production of a CVC word, such as $/ \mathrm{dog} /$, the potential variables include the initial consonant ( $\mathrm{C} i$ ), the vowel $(V)$, and the final consonant $(C)$. The editing view of speech planning predicts a benefit for repeating value assignments to variables actually used in the plan. In other words, the editing view predicts that repeating a unit should be beneficial, relative to conditions in which the unit is not repeated. Our results are consistent with this editing view of speech planning. In particular, we demonstrated that the abstract syllabic structure (independently of its phonological content) plays an important role in speech production.

\section{REFERENCES}

CosTA, A. (1995, July). Suprasegmental structures in phonological encoding. Paper presented at the European Summer School on "Aspects of Speech Production," University of Birmingham, Birmingham, U.K.

Costa, A. (1997). La codificación fonológica en la producción del lenguaje: Unidades y procesos implicados [Phonological encoding in speech production: Units and processes]. Unpublished doctoral dissertation, University of Barcelona, Spain.

DELL, G. S. (1986). A spreading-activation theory of retrieval in sentence production. Psychological Review, 93, 283-321.

Ferrand, L., Grainger, J., \& Segui, J. (1994). A study of masked form priming in picture and word naming. Memory \& Cognition, 22, 431-441.

Ferrand, L., Segui, J., \& Grainger, J. (1996). Masked priming of word and picture naming: The role of syllabic units. Journal of Memory \& Language, 35, 708-723. 
Ferrand, L., Segul, J., \& Humphreys, G. W. (1997). The syllable's role in word naming. Memory \& Cognition, 25, 458-470.

IMBS, P. (1971). Études statistiques sur le vocabulaire français: Dictionnaire des fréquences [Statistical studies on French: French language frequency counts]. Vocabulaire littéraire des XIXe et XXe siècles (Trésor de la langue française). Nancy: CNRS.

LeVelt, W. J. M. (1989). Speaking: From intention to articulation. Cambridge, MA: MIT Press.

MACKAY, D. (1987). The organization of perception and action: $A$ theory for language and other cognitive skills. New York: SpringerVerlag.

Mehler, J., Dommergues, J., Frauenfelder, U., \& Segui, J. (1981). The syllable's role in speech segmentation. Journal of Verbal Learning \& Verbal Behavior, 20, 298-305.

MeiJer, P. J. A. (1996). Suprasegmental structures in phonological encoding: The CV structure. Journal of Memory \& Language, 35, 840-853.

ROMANI, C. (1992). The representation of prosodic and syllabic structure in speech production. Unpublished doctoral dissertation, Johns Hopkins University.

Rosenbaum, D. A., Weber, R. J., Hazelett, W. M., \& Hindorff, V. (1986). The parameter remapping effect in human performance:
Evidence from tongue twisters and finger fumblers. Journal of Memory \& Language, 25, 710-725.

Sevald, C. A., \& Dell, G. S. (1994). The sequential cueing effect in speech production. Cognition, 53, 91-127.

Sevald, C. A., Dell, G. S., \& Cole, J. S. (1995). Syllable structure in speech production: Are syllables chunks or schemas? Journal of Memory \& Language, 34, 807-820.

WheEldon, L. R., \& Levelt, W. J. M. (1995). Monitoring the time course of phonological encoding. Journal of Memory \& Language, 34, 311-334.

\section{NOTES}

1. Throughout the article, we denote syllable structure using a dot (e.g., BAL.CONY).

2. The "@" represents the phoneme schwa.

3. This point was raised by one of the reviewers.

(Manuscript received March 3, 1997;

revision accepted for publication September 26, 1997.) 